\section{Korean Guidelines for Cardiopulmonary Resuscitation. Part 8. Neonatal resuscitation}

\author{
Ju Sun Heo ${ }^{1 *}$, Su Yeong Kim ${ }^{2 *}$, Hye Won Park ${ }^{3 *}$, Yong-Sung Choi ${ }^{4}$, \\ Chan-Wook Park ${ }^{5}$, Geum Joon $\mathrm{Cho}^{6}$, Ah Young $\mathrm{Oh}^{7}$, Eun Kyung Jang ${ }^{8}$, \\ Han-Suk Kim ${ }^{9}$, Ai-Rhan Ellen Kim ${ }^{10}$, Sung Oh Hwang ${ }^{11}$; on behalf of \\ the Steering Committee of 2020 Korean Guidelines for \\ Cardiopulmonary Resuscitation and Emergency Cardiovascular Care
}

\author{
'Department of Pediatrics, Korea University College of Medicine, Seoul, Korea \\ ${ }^{2}$ Department of Pediatrics, Chung-Ang University College of Medicine, Seoul, Korea \\ ${ }^{3}$ Department of Pediatrics, Konkuk University School of Medicine, Seoul, Korea \\ ${ }^{4}$ Department of Pediatrics, Kyung Hee University School of Medicine, Seoul, Korea \\ ${ }^{5}$ Department of Obstetrics and Gynecology, Seoul National University College of Medicine, Seoul, Korea \\ ${ }^{6}$ Department of Obstetrics and Gynecology, Korea University College of Medicine, Seoul, Korea \\ ${ }^{7}$ Department of Anesthesiology and Pain Medicine, Seoul National University College of Medicine, Seoul, \\ Korea \\ ${ }^{8}$ Office of Patient Safety, Yonsei University Severance Hospital, Seoul, Korea \\ ${ }^{9}$ Department of Pediatrics, Seoul National University College of Medicine, Seoul, Korea \\ ${ }^{10}$ Department of Pediatrics, Ulsan University College of Medicine, Seoul, Korea \\ ${ }^{11}$ Department of Emergency Medicine, Yonsei University Wonju College of Medicine, Wonju, Korea
}

elSSN: $2383-4625$

Received: 7 March 2021

Revised: 3 April 2021

Accepted: 5 April 2021

Correspondence to: Han-Suk Kim Department of Pediatrics, Seoul National University Children's Hospital, Seoul National University College of Medicine, 101 Daehak-ro, Jongno-gu, Seoul 03080, Korea

E-mail:kimhans@snu.ac.kr ORCID

https://orcid.org/0000-0002-9777-3231

*These three authors contributed equally to this work as first authors.

\title{
OUTLINE
}

The transition from the intrauterine to extrauterine environment occurring at birth requires several interdependent physiological processes to successfully adapt from placental gas exchange to pulmonary respiration. ${ }^{1}$ As newborns breathe through the lungs, pulmonary vascular resistance rapidly decreases; consequently, the pulmonary blood flow increases. This increases the left ventricular filling and cardiac output, which maintains the coronary artery and cerebral blood flow. ${ }^{2}$

Unlike approximately 85\% of term newborns who start breathing spontaneously within 10 to 30 seconds of birth, ${ }_{1}^{3}$ approximately 10\% require tactile stimulation to breathe. ${ }^{4}$ Moreover, $5 \%$, $2 \%, 0.1 \%$, and $0.05 \%$ of term newborns require positive-pressure ventilation (PPV), endotracheal intubation, chest compression, and chest compression with epinephrine, respectively. ${ }^{5-8} \mathrm{Al}-$ though most infants initiate successful respiration without intervention, appropriate resuscitation can prevent complications and save millions of newborns worldwide.

The 2020 Korean Neonatal Resuscitation guideline is a medical recommendation based on scientific evidence for neonatal resuscitation. This guideline is based on the Consensus on Science with Treatment Recommendations (CoSTR) suggested by the International Liaison Committee on Resuscitation (ILCOR) in 2020,9-11 and studies on neonatal resuscitation have been further reviewed. For revised items of high clinical importance and requiring further review, evidence was reviewed through adaptation or hybridization, and a meta-analysis or scoping review was performed.

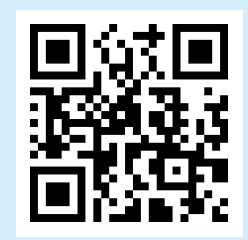

How to cite this article:

Heo JS, Kim SY, Park HW, Choi YS, Park CW, Cho GJ, Oh AY, Jang EK, Kim HS, Kim AE, Hwang SO; on behalf of the Steering Committee of 2020 Korean Guidelines for Cardiopulmonary Resuscitation and Emergency Cardiovascular Care. 2020 Korean Guidelines for Cardiopulmonary Resuscitation. Part 8. Neonatal resuscitation. Clin Exp Emerg Med 2021;8(S):S96-S115. https://doi.org/10.15441/ceem.21.028

This is an Open Access article distributed under the terms of the Creative Commons Attribution Non-Commercial License (https:// creativecommons.org/licenses/by-nc/4.0/). 


\section{Level of evidence and recommendation of class}

The levels of evidence were divided into levels $A-C$, with $A$ as the highest and $C$ as the lowest level, using the American Heart Association's definition. ${ }^{12}$ Level A refers to high-quality evidence from more than one randomized controlled trials (RCTs), metaanalyses of high-quality RCTs, or one or more RCTs collaborated through high-quality registry studies. Level B-R (randomized) refers to moderate-quality evidence from one or more RCTs, or meta-analyses of moderate-quality RCTs. Level B-NR (non-randomized) refers to moderate-quality evidence from one or more welldesigned, well-executed, non-randomized studies, observational studies, or registry studies or meta-analyses of such studies. Level C-LD (limited data) refers to evidence based on randomized or non-randomized observational or registry studies with limitations of design or execution, meta-analyses of such studies, or physiological or mechanical studies in human subjects. Additionally, Level C-EO (expert opinion) refers to consensus of expert opinion based on clinical experiences.

The class of recommendation was evaluated based on the direction (benefit/harm) and strength (strong/weak recommendations) using the GRADE (Grading of Recommendations, Assessment, Development and Evaluations) method and was classified into three categories used by the American Heart Association. ${ }^{12,13}$ Class I was assigned when the benefit of the treatment or intervention was significantly high relative to the risk (appropriate for most clinicians to provide the treatment or intervention to most patients). Class Ila and Ilb were assigned when the treatment or intervention was generally useful (appropriate for most clinicians to provide the treatment or intervention, with some important exceptions), and when the treatment or intervention had positive effects without clear evidence, respectively. Class III (no benefit) was assigned when the treatment or intervention was ineffective (if high-quality studies did not demonstrate the effects), and Class III (harm) referred to treatment or intervention where the risk overrides the benefit.

\section{Major changes in 2020 neonatal resuscitation guidelines and summary of the neonatal resuscitation algorithm Major changes to the neonatal resuscitation guidelines in 2020}

Intended subjects for neonatal resuscitation Neonatal resuscitation is generally performed for 'newly born' infants. However, neonatal resuscitation can be performed in cases of cardiovascular failure caused by gas exchange disorders within several weeks of birth after the transition period.
Umbilical cord management

Based on the findings of a large-scale multicenter RCT, cord milking increases the frequency of intraventricular hemorrhage in extremely preterm newborns with a gestational age (GA) $<28$ weeks; therefore, it is not recommended to milk the cord in such newborns (Class III: no benefit, Level B-R).

'Non-vigorous' newborns delivered through meconium-stained amniotic fluid Studies conducted after the guidelines were changed in 2015 demonstrated that routine laryngoscopy with or without tracheal suctioning was not beneficial. More emphasis is placed on helping newborns quickly restore their breathing by applying PPV instead of direct laryngoscopy and endotracheal suctioning (Class Ilb, Level C-LD).

\section{Sustained inflation}

In a study on a group of preterm newborns with a $\mathrm{GA}<28$ weeks, PPV with sustained inflation of $\geq 1$ second increased the risk of mortality before discharge. Therefore, sustained inflation of initial breathing should not be performed in preterm newborns with PPV caused by bradycardia or inappropriate breathing at birth (Class III: harm, Level C-LD).

\section{Oxygen administration}

When initial respiratory support, such as continuous positive airway pressure (CPAP) or PPV, is provided in preterm newborns with a GA $<35$ weeks, starting with low oxygen concentrations $(21 \%-30 \%)$, may be considered instead of high concentrations (Class Ilb, Level C-LD). An oxygen blender should be used to provide the correct oxygen concentration recommended for preterm newborns. When an oxygen blender is unavailable, adjusting oxygen flow using a self-inflating bag with a reservoir may be a useful method of titrating oxygen.

In term and late preterm newborns (a GA $\geq 35$ weeks) receiving respiratory support at birth, initial use of $21 \%$ oxygen is recommended (Class Ilb, Level C-LD); 100\% oxygen should not be used (Class III: harm, Level C-LD).

\section{Timing of discontinuing resuscitation}

If all the resuscitation steps are completed and continuous cardiopulmonary resuscitation (CPR) is still required, as spontaneous circulation has not been restored after excluding reversible causes, discontinuation of CPR may be discussed with the team and the family at 10 to 20 minutes after birth (Class Ilb; Level C-LD). 


\section{Summary of neonatal resuscitation algorithm (Fig. 1)}

Umbilical cord management

Cord clamping can be performed with a delay of $\geq 30$ seconds in term or preterm newborns who do not require resuscitation at birth. However, in newborns with unstable breathing and who do not cry, delayed cord clamping (DCC) may hinder respiratory support. Thus, DCC cannot be routinely applied to these newborns.

\section{Three rapid evaluation questions}

Responses to the following questions must be assessed to determine whether resuscitation is required. Preterm newborn? Weak muscle tone? Weak crying or breathing?

If none of these questions are answered, newborns can be transferred to their mothers and can undergo the initial steps while maintaining skin-to-skin contact. However, if the newborn meets even one of these criteria, they need to be transferred to a radiant warmer for resuscitation.

Initial steps

These include warming, maintaining temperature, opening the airway, suctioning as needed, drying, and tactile stimulation.

\section{Assessment of respiration and heart rates}

- If the newborn has a heart rate $>100$ beats/min and shows labored breathing or persistent cyanosis, oxygen saturation needs to be monitored using a pulse oximeter. Oxygen needs to be sup-

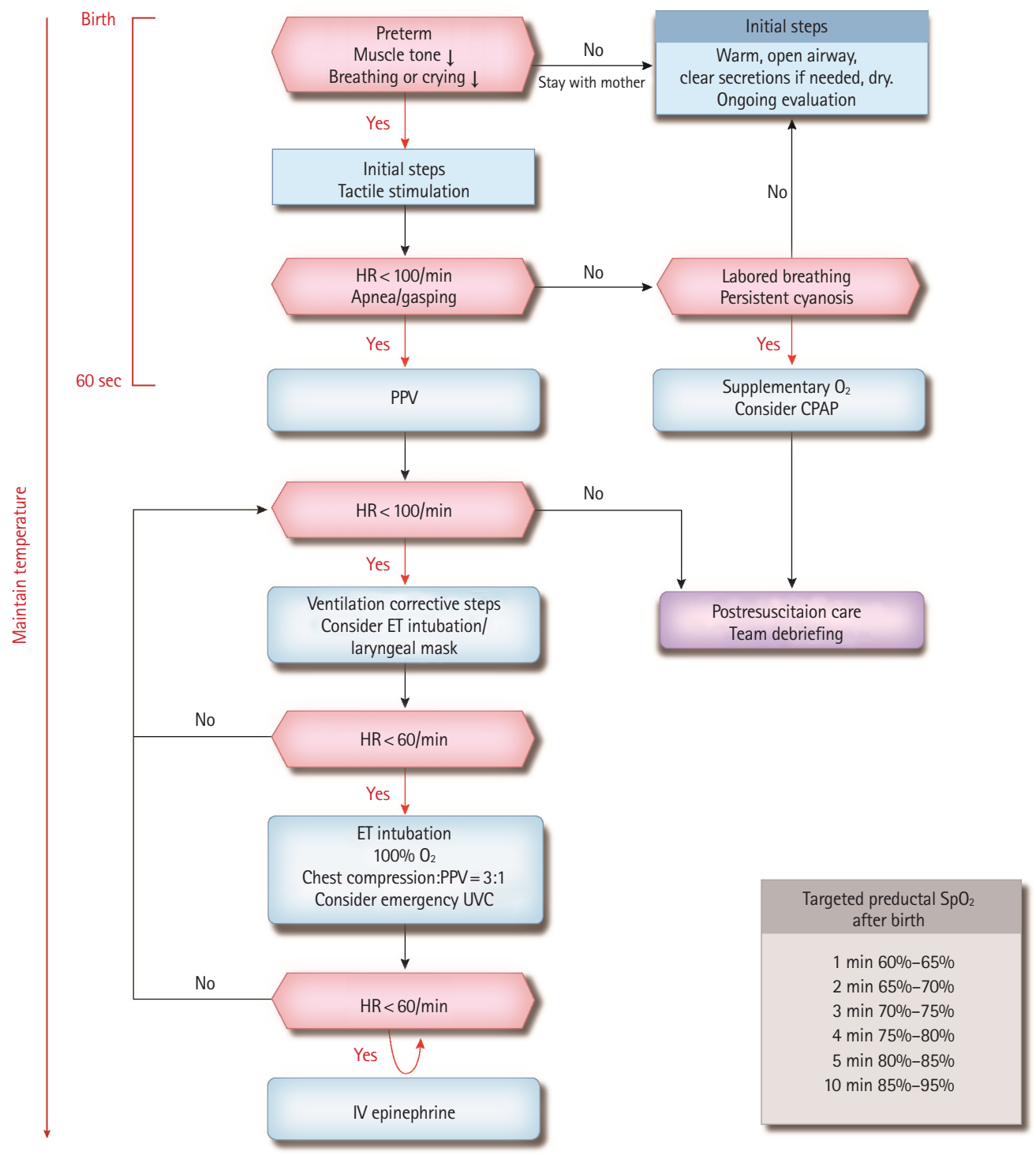

Fig. 1. Neonatal resuscitation algorithm. HR, heart rate; PPV, positive-pressure ventilation; CPAP, continuous positive airway pressure; ET, endotracheal; UVC, umbilical venous catheter; IV, intravenous; $\mathrm{O}_{2}$, oxygen; $\mathrm{SpO}_{2}$, saturation of percutaneous oxygen. 
plied if necessary; CPAP can be considered.

- If the newborn has a heart rate $<100$ beats/min or shows apnea or gasping, electrocardiogram (ECG) monitoring needs to be considered along with monitoring oxygen saturation, and PPV should be performed immediately. Remember that initial steps, re-assessment, and respiratory support must be initiated within 60 seconds after birth ("the Golden Minute").

\section{PPV}

If the chest movement is insufficient or heart rate is still $<100$ beats/min during PPV, corrective ventilation steps must be performed. If bag-mask ventilation is unsuccessful, endotracheal intubation or insertion of a laryngeal mask airway should be considered.

\section{Chest compressions}

If the heart rate is $<60$ beats/min even after adequate PPV is applied for $>30$ seconds, endotracheal intubation should be performed. Chest compression and PPV are performed at a 3:1 ratio. If there is no response to low oxygen concentration, it can be increased to $100 \%$. Inserting an emergency umbilical venous catheter may be considered to administer additional drugs and plasma volume expanders.

\section{Medications and volume expansion}

If the heart rate is consistently $<60$ beats/min despite adequate PPV and chest compressions for $>60$ seconds, intravenous epinephrine can be administered. If there is no response, other causes, such as hypovolemia and pneumothorax, must be considered. If there is no response to resuscitation and actual or suspected blood loss occurs, a plasma volume expander should be administered.

\section{TARGETS OF NEONATAL RESUSCITATION}

Neonatal resuscitation is applied to 'newly born' infants who are in the process of adapting from the intrauterine to extrauterine environment. However, neonatal resuscitation can still be performed after the transition period within a few weeks of birth if the primary cause of cardiovascular failure is gas exchange disorder. However, if the heart is the suspected primary cause, a higher ratio of chest compression to ventilation (e.g., 15:2) may be considered. ${ }^{14}$

\section{PREDICTING THE NEED FOR RESUSCITATION}

Adequate preparation for neonatal resuscitation requires assessing perinatal risk factors, a system wherein appropriate medical personnel can be mobilized according to the risk level, ready-touse medical equipment and supplies, effective teamwork, and clinicians with proficient medical techniques. Moreover, at least one medical staff member who can perform neonatal care, initial steps, and PPV is required. If a newborn has serious perinatal risk factors that may require resuscitation, additional personnel who can perform chest compression, endotracheal intubation, and emergency insertion of an umbilical venous catheter are required. ${ }^{15,16} \mathrm{New}-$ borns without perinatal risk factors may also require unexpected resuscitation; therefore, each hospital must always have the necessary personnel available for neonatal resuscitation. Inadequate preparation and malfunctioning equipment prevent effective resuscitation; thus, a standardized checklist is recommended. In preterm newborns or those with perinatal risk factors, equipment to maintain body temperature and assist breathing is required.

When delivering newborns with perinatal risk factors, a team for resuscitation should be formed, and a team leader must be chosen. If there is time, a briefing should be conducted before resuscitation, and roles must be divided among the team members by predicting the procedure required for the newborn. ${ }^{17,18}$ Effective communication and cooperation among team members are critical for successful resuscitation and survival of the newborn.

\section{UMBILICAL CORD MANAGEMENT}

For term or late preterm newborns who do not require resuscitation, DCC may be considered until respiration and activity of the newborn are assessed when they are in contact with the mother (Class Illb, Level C-LD). Early cord clamping within 30 seconds of birth can disrupt the transition, as fetal blood may remain in the placenta without entering the newborn's circulatory system. A DCC of $\geq 30$ seconds is reportedly associated with higher levels of hematocrit after birth and improved levels of iron during infancy. ${ }^{19-31}$ In preterm newborns who do not require resuscitation, DCC may be effective as it lowers the need for blood pressure management and blood transfusion and improves survival (Class Ila, Level B-R). ${ }^{32-39}$ However, there is little evidence supporting early or DCC in term or preterm newborns who require resuscitation at birth (Class IIb, Level C-EO). ${ }^{16}$

Early cord clamping must be considered in cases with a possibility of placental transfusion, such as maternal bleeding, hemodynamic instability, placental abruption, and placenta previa.

Cord milking is a possible alternative to DCC; however, a largescale multicenter RCT reported that cord milking increased the frequency of intraventricular hemorrhage in extremely preterm newborns with a GA $<28$ weeks. ${ }^{40}$ Thus, cord milking should not be performed in such newborns (Class III: no benefit, Level B-R). 


\section{INITIAL STEPS}

The initial steps of neonatal resuscitation include warming, maintaining body temperature, adopting the sniffing position to secure the airway, suctioning, wiping the amniotic fluid with a dry cloth (or wrapping in a plastic bag for preterm newborns with a $\mathrm{GA}<32$ weeks), and tactile stimulation for breathing.

\section{Maintaining the appropriate body temperature}

After birth, this is an initial step of neonatal stabilization; body temperature at admission in non-asphyxiated newborns is an important predictor of mortality. ${ }^{41}$ Hypothermia (temperature $<36^{\circ} \mathrm{C}$ ) is associated with serious sequelae, including intraventricular hemorrhage, respiratory failure, hypoglycemia, and late-onset sepsis. ${ }^{42-44}$ Therefore, body temperature on admission must be measured and recorded as prognostic predictors and quality indicators (Class I, Level B-NR). ${ }^{1}$ A body temperature of $36.5^{\circ} \mathrm{C}$ to $37.5^{\circ} \mathrm{C}$ is recommended on admission and at rest for non-asphyxiated newborns (Class I, Level C-EO). ${ }^{45}$

\section{Methods to maintain body temperature in the delivery room}

Although a radiant warmer, hat, and plastic bag can help maintain body temperature, they do not completely prevent hypothermia in preterm newborns. Therefore, increased room temperature $\left(23^{\circ} \mathrm{C}-25^{\circ} \mathrm{C} \text {, or } \geq 25^{\circ} \mathrm{C} \text { if the } \mathrm{GA} \text { is }<28 \text { weeks }\right)^{14}$ heating mats, and warm humidified air are also required.

Newborns with a GA $\geq 32$ weeks must be wiped with a cloth immediately and covered with pre-warmed clothes around the head and body except for the face. If CPR is required, resuscitation can be performed under a radiant warmer; if not, skin-toskin contact with the mother is needed (Class Ila, Level B-R). ${ }^{46}$

In newborns with a GA $<32$ weeks, several methods like using a radiant warmer, plastic bag, and heating mat, ${ }^{47-51}$ warm humidified air when a ventilator is needed, ${ }^{52,53}$ and increasing the room temperature/wearing a hat/heating $\mathrm{mat}^{54-57}$ are recommended (Class IIb, Level B-R, B-NR, C-LD). ${ }^{58}$ Previous studies have reported concerns about hyperthermia. ${ }^{44,59}$ Therefore, hyperthermia above $38.0^{\circ} \mathrm{C}$ should be avoided due to the potential associated risks (Class Ila, Level C-LD).

There is a high risk of hypothermia if a newborn is delivered outside the hospital. Therefore, the newborn must be wiped with a cloth immediately after delivery and wrapped in plastic bags and cloth. Those born at a GA of $\geq 30$ weeks need to maintain appropriate body temperature through skin-to-skin contact with the mother during transfer to the hospital (Class Ilb, Level C-LD). ${ }^{60,61}$

\section{Warming hypothermic newborns}

It is generally accepted that slowly raising the body temperature of hypothermic newborns after resuscitation may reduce complications such as apnea and arrhythmia. However, there is a lack of evidence to determine which is more effective: increasing the body temperature rapidly $\left(>0.5^{\circ} \mathrm{C} / \mathrm{hr}\right)$ or slowly $\left(<0.5^{\circ} \mathrm{C} / \mathrm{hr}\right)$. Thus, both methods can be used for hypothermic newborns (Class Ill, Level C-LD). 3,16,17,62,63

\section{Effects of maternal hypothermia and hyperthermia on newborns}

Maternal hyperthermia during labor is associated with poor prognosis, including increased mortality, convulsions, and encephalopathy in newborn ${ }^{64-74}$; this is in contrast to maternal hypothermia, which is not associated with a clinically significant poor prognosis in newborns. ${ }^{75-79}$ Although maternal hyperthermia is associated with poor prognosis in newborns, there is insufficient evidence for the effect of treatment of maternal hyperthermia on the prognosis of newborns.

\section{Maintaining body temperature in resource-limited settings}

The mortality rate increases in proportion to the severity of hypothermia at a body temperature $\leq 36.5^{\circ} \mathrm{C}$. Therefore, it is important to maintain the body temperature in resource-limited settings. ${ }^{80}$ Compared with term newborns, preterm newborns show a higher risk of hypothermia; preventing hypothermia after birth (within 1-2 hours) can help decrease mortality. In resource-limited settings, the newborn can be wrapped in a plastic bag up to the neck or wiped and wrapped with a cloth to maintain normal body temperature during the transition (1-2 hours after birth) (Class Ilb, Level C-LD). ${ }^{61,81}$ Other alternatives include breastfeeding with skin-to-skin contact and kangaroo care (Class Ilb, Level CLD). ${ }^{82-89}$ However, few studies are available about the use of plastic bags or skin-to-skin contact during the stabilization period after resuscitation.

\section{Clearing the airway Non-meconium stained amniotic fluid}

Suctioning of amniotic fluid using a bulb syringe or suction catheter does not help remove fluid from the lungs. Instead, it can cause side effects such as infection, bradycardia, apnea, hypoxia, decreased arterial oxygen tension, hypercapnia, failure to control cerebral blood flow, increased intracranial pressure, neonatal brain injury, ${ }^{90-99}$ and delayed ventilation in those without spontaneous breathing. ${ }^{3,100}$ Therefore, routine oropharyngeal or nasopharyngeal suctioning immediately after delivery is not recommended (Class 
Ilb, Level C-LD). ${ }^{9-11,101}$ Suctioning may be considered only if the airway appears obstructed or PPV is required (Class IIb, Level C-EO). ${ }^{3}$

\section{Meconium stained amniotic fluid}

Meconium stained amniotic fluid (MSAF) may indicate fetal distress; these newborns may require resuscitation, including endotracheal intubation after delivery. Therefore, trained personnel and equipment for endotracheal intubation must be prepared in advance.

If a newborn delivered with MSAF is 'vigorous' (heart rate $\geq 100$ beats/min, good respiratory effort, and good muscle tone), routine suctioning of meconium immediately after the head delivers but before the shoulders deliver is no longer recommended. ${ }^{102}$ The newborn may stay with the mother to receive the initial steps of newborn care. However, the meconium around the mouth and nose can be gently removed using a bulb syringe and suction catheter.

Since 2015, the guideline for the 'non-vigorous' (heart rate $<100$ beats/min, weak muscle tone, inadequate breathing effort) newborn delivered from MSAF has changed; routine intubation and tracheal suctioning are no longer required. Subsequently, four RCTs and three observational studies showed that direct laryngoscopy and tracheal suctioning did not have beneficial effects on survival at discharge, cognitive and motor development abnormalities, hypoxic ischemic encephalopathy, meconium aspiration syndrome, respiratory support, chest compression and use of epinephrine in the delivery room, and length of hospital stay. ${ }^{103-}$ 109 Thus, the effects of direct laryngoscopy and tracheal suctioning for 'non-vigorous' newborns with MSAF are unclear, and PPV is required to speed up the restoration of breathing (Class Ilb, Level C-LD). However, endotracheal intubation and tracheal suctioning may be necessary if airway obstruction is suspected during PPV. (Class Ila, Level C-EO).

\section{Tactile stimulation}

Additional stimulation is necessary when no spontaneous breathing effort is observed in the initial steps (Class Ila, Level B-NR). ${ }^{110}$ Stimulation methods include short and gentle rubbing of the back, trunk, and extremities using a pre-warmed cloth and light tapping of the feet two to three times. ${ }^{111-113}$ Vigorous shaking of the newborn does not help restore breathing and may be harmful. If apnea continues after stimulation, PPV must be started immediately. ${ }^{111}$

\section{PHYSIOLOGICAL MONITORING AND FEEDBACK EQUIPMENT}

\section{Heart rate evaluation}

Heart rate assessment of newborns immediately after birth is essential in determining the effectiveness of spontaneous breathing and the need for resuscitation. An increased heart rate during resuscitation is the most sensitive indicator of the response to each step. Therefore, it is crucial to evaluate the heart rate rapidly and accurately.

Although auscultation is the preferred way to assess heart rate in the initial evaluation, it is inaccurate and less reliable. ${ }^{46,114}$ When comparing an ECG with pulse oximeter for continuous heart rate assessment, the pulse oximeter required more time to measure the heart rate, and the heart rate was underestimated during the initial 2 minutes. ${ }^{115-117}$ Comparatively, ECG is the fastest and most accurate way to measure the heart rate. ${ }^{118-121}$ A 3-lead ECG could be useful for assessing heart rate in preterm and term newborns who require resuscitation (Class Ilb, Level C-LD). During chest compressions, an ECG is recommended to rapidly and accurately assess heart rate (Class Ila, Level C-EO). However, ECG cannot replace a pulse oximeter that evaluates the oxygenation level in newborns.

\section{Respiratory function evaluation tool}

Evaluation tools for respiratory function are useful in preventing excessive pressure and ventilation. ${ }^{122}$ An exhaled carbon dioxide $\left(\mathrm{CO}_{2}\right)$ monitor is useful for evaluating gas exchange during PPV with a face mask. ${ }^{123}$ However, it is unclear whether it improves prognosis (Class Ilb, Level C-LD).

\section{VENTILATION AND OXYGENATION}

\section{Sustained inflation}

In 2015, the ILCOR did not recommend using sustained inflation., ${ }^{1,124}$ In 2020, the ILCOR conducted a systematic review of 10 RCTs with 1,502 newborns. ${ }^{125-134}$ This review concluded that sustained inflation showed no significant reduction in mortality, the need for mechanical ventilation, bronchopulmonary dysplasia, and air leakage. Moreover, a study on preterm newborns with a $\mathrm{GA}<28$ weeks showed that PPV with sustained inflation of $\geq 1$ second increased the potential risk of mortality before discharge. ${ }^{133}$ Therefore, sustained inflation of initial breathing should not be performed in preterm newborns with PPV for bradycardia or inadequate breathing effort at birth (Class III: harm, Level C-LD). In term or late preterm newborns undergoing PPV, there is insufficient evidence to suggest an appropriate duration of sustained inflation.

\section{Positive end-expiratory pressure}

Although providing positive end-expiratory pressure (PEEP) to newborns requiring PPV likely helps prevent lung collapse at the end of expiration, human studies are limited. In 2015, ILCOR con- 
ducted a review that showed that additional PEEP did not reduce the incidence of mortality, endotracheal intubation, chest compression, and drug use in preterm newborns. Moreover, the heart rate did not rapidly improve, and air leakage, bronchopulmonary dysplasia, and Apgar scores were also unaffected. However, PEEP reduced the maximum amount of oxygen; thus, PEEP was suggested for resuscitation in the delivery room. ${ }^{1,124,135}$ As there are no additional studies, we recommend that a PEEP of $\geq 5 \mathrm{~cm} \mathrm{H} \mathrm{H}_{2} \mathrm{O}$ be provided to preterm newborns who undergo PPV in the delivery room (Class Illb, Level C-LD). For term newborns, evidence suggesting PEEP is lacking.

\section{Tools for PPV and advanced airway management Comparison of the effects of a T-piece resuscitator and a self-inflating bag}

PPV can be effectively induced using a flow-inflating bag, selfinflating bag, and a T-piece resuscitator depending on the level of experience and preference (Class Ila, Level B-R). ${ }^{136,137}$ A selfinflating bag is a useful tool for delivering PPV when compressed gas is unavailable. However, it cannot provide CPAP as other tools, nor can it maintain PEEP during PPV..$^{138-141}$ In contrast, a flow-inflating bag requires training for effective use. A T-piece resuscitator is easier to use, and it can continuously provide the targeted inspiratory pressure for a longer period. ${ }^{142-144}$ However, there is no clear evidence that T-piece resuscitators can improve prognosis. ${ }^{136,137}$ Two additional studies published after guideline revision in 2015 demonstrated that the use of a T-piece resuscitator increased the survival rate and decreased bronchopulmonary dysplasia and the need for endotracheal intubation in the delivery room. ${ }^{145,146}$ However, there is insufficient evidence to recommend the use of a T-piece resuscitator or a self-inflating bag in newborns receiving PPV (Class indeterminate). Nevertheless, a T-piece resuscitator may be considered in facilities equipped with compressed gas (Class Ilb, Level C-LD).

\section{Laryngeal mask airway}

A laryngeal mask can help induce effective ventilation in term and preterm newborns with a GA $\geq 34$ weeks. However, evidence for preterm newborns with a GA $<34$ weeks or weight $<2 \mathrm{~kg}$ is lacking. When facial mask ventilation is inefficient, a laryngeal mask can be used instead of endotracheal intubation (Class Ilb, Level B-R). ${ }^{147}$ The use of a laryngeal mask is recommended when endotracheal intubation fails or is impossible in term newborns and preterm newborns with a GA $>34$ weeks (Class I, Level C-EO). The use of a laryngeal mask during chest compression and drug administration has not been assessed.

\section{Positioning the endotracheal tube in the airway}

During resuscitation, endotracheal intubation is required when inefficient PPV is continued, continuous PPV is required, chest compression is necessary, or in special circumstances such as the presence of a congenital diaphragmatic hernia. Successful ventilation induced by endotracheal intubation is indicated by an increased heart rate. An exhaled $\mathrm{CO}_{2}$ detector is the most useful device to determine the position of the endotracheal tube in the airway. When no exhaled $\mathrm{CO}_{2}$ is detected, insertion of the tube into the esophagus is suspected. However, when the pulmonary blood flow is reduced in cardiac arrest, the exhaled $\mathrm{CO}_{2}$ detector shows false negatives despite correct tube position, which can lead to unnecessary reintubation in critical newborns. Signs such as chest movement, breathing sounds symmetrically audible in both lung fields on auscultation, and condensation of water vapor in the tube can be used to correct the tube's position in the airway.

\section{CPAP}

In three RCTs with 2,358 preterm newborns with a GA $<30$ weeks, initial CPAP use was more beneficial than PPV after endotracheal intubation. ${ }^{148-150}$ Initial CPAP lowers the rate of endotracheal intubation in the delivery room and reduces the period of mechanical ventilation while lowering the mortality rate and frequency of bronchopulmonary dysplasia. Additionally, the incidence of side effects such as air leakage and intraventricular hemorrhage does not increase following initial CPAP. For spontaneously breathing preterm newborns who require respiratory support immediately after delivery, it is recommended to use CPAP, not intubation (Class Ilb, Level B-R).

\section{Assessment of oxygen need and oxygen administration Use of a pulse oximeter}

The use of a pulse oximeter is recommended when resuscitation is expected, PPV is required, central cyanosis persists for 5 to 10 minutes after birth, or oxygen administration is required.

\section{Oxygen administration}

Term and late preterm newborns (a GA $\geq 35$ weeks) The debate on the risk of hypoxia and the risk of exposure to excessive oxygen in term and late preterm newborns who require respiratory support at birth continues. In 2019, the ILCOR conducted a systematic review and meta-analysis of five RCTs and five quasi-RCTs comprising 2,164 newborns. ${ }^{151}$ The results demonstrated that starting resuscitation with 21\% oxygen was more beneficial in reducing short-term mortality than with 100\% oxy- 
gen in term and preterm newborns with a GA $\geq 35$ weeks. However, there was no difference in the rates of hypoxic ischemic encephalopathy and moderate-to-severe neurodevelopmental impairment. No previous study has investigated starting resuscitation with intermediate oxygen concentrations.

In term and late preterm newborns (a $G A \geq 35$ weeks) receiving respiratory support at birth, the initial use of $21 \%$ oxygen is recommended (Class Illb, Level C-LD); 100\% oxygen should not be used (Class III: harm, Level C-LD). Subsequent oxygen administration can be adjusted depending on whether the pre-ductal oxygen saturation target is achieved according to the standard set for healthy term newborns. ${ }^{152}$

Preterm newborns with a $\mathrm{GA}<35$ weeks

In 2019, a systematic review and meta-analysis of RCTs ${ }^{153-164}$ and four cohort studies ${ }^{165-168}$ published until August 2018 was conducted by the ILCOR. ${ }^{169}$ Subsequently, a meta-analysis including one more RCTs published in $2019^{170}$ was conducted for the Korean CoSTR. No difference was observed in short- or long-term mortality when respiratory support was started with low (21\%-30\%) compared with high (60\%-100\%) oxygen concentrations in preterm newborns with a GA $<35$ weeks. Additionally, high oxygen concentrations were not beneficial in preventing neurodevelopmental impairment, retinopathy of prematurity, bronchopulmonary dysplasia, and necrotizing enterocolitis.

When initial respiratory support, such as CPAP or PPV, is provided in preterm newborns with a $\mathrm{GA}<35$ weeks, starting with low oxygen concentrations (21\%-30\%) may be considered instead of high oxygen concentrations (60\%-100\%) (Class Illb, Level C-LD). An oxygen blender should be used to provide the correct oxygen concentration recommended for preterm newborns. When an oxygen blender is unavailable, adjusting the oxygen flow using a self-inflating bag with a reservoir may be a useful method of titrating oxygen. ${ }^{171}$

\section{CHEST COMPRESSIONS}

Initiating chest compression is reasonable if the heart rate is $<60$ beats/min despite adequate PPV for at least 30 seconds (Class Ila, Level C-EO). ${ }^{1,16,135}$ Chest compression must be performed on the lower $1 / 3$ of the sternum, ${ }^{172,173}$ and the depth of compression should be at least $1 / 3$ of the anteroposterior diameter of the chest (Class IIb, Level C-LD). ${ }^{174}$ There are two techniques to perform chest compression. The first is to use the thumbs of both hands and surround the rib cage with the remaining fingers supporting the back (two-thumb encircling hands technique). The second is to use two fingers of one hand and support the back with the other hand (two-finger technique). The two-thumb encircling hands technique may generate higher blood pressure, higher coronary perfusion pressure, and lower fatigue for the performers. ${ }^{175-178}$ The two-thumb encircling hands technique may be a better technique for cardiac compression in newborns (Class Ilb, Level C-LD), and can be continued from the head of the newborns while accessing the umbilical venous catheter.

It is recommended to perform synchronized chest compressions and PPV at a ratio of 3:1 (three compressions and one PPV) (Class IIb, Level C-LD). ${ }^{1,124,135,179-183}$ Approximately 120 compressions and ventilations need to occur within 1 minute, and each action should last 0.5 seconds. If cardiopulmonary failure is of cardiac origin, a higher ratio of 15:2 may be used (Class Illb, Level C-EO). ${ }^{14}$

No previous clinical study has assessed the adequate level of inhaled oxygen during chest compressions. In a meta-analysis of eight animal studies, administration of 100\% oxygen did not result in significantly better effects than administration of $21 \%$ oxygen. ${ }^{184}$ Nonetheless, when there is no response at low oxygen concentrations during chest compressions, the oxygen concentration may be increased up to 100\% (Class Ilb, Level C-EO). After the heart rate is restored, the oxygen concentration must be lowered immediately to reduce the risk of complications caused by hyperoxia. ${ }^{1,16,135}$

Heart rate is the best indicator to assess the progression of neonatal resuscitation. The exhaled $\mathrm{CO}_{2}$ detector and pulse oximeter may also help evaluate the recovery of spontaneous circulation. ${ }^{185}$ However, their effects have not been demonstrated in newborns with asystole or bradycardia. Therefore, the routine use of exhaled $\mathrm{CO}_{2}$ detector and pulse oximeter is not recommended to determine the recovery of spontaneous circulation (Class Ilb, Level C-LD).

\section{MEDICATIONS AND VOLUME EXPANSION}

Drugs are not commonly used in neonatal resuscitation. Bradycardia in newborns is mostly caused by insufficient lung expansion and severe hypoxia; both are often corrected by adequate ventilation. However, if the heart rate is $<60$ beats/min despite adequate ventilation with 100\% oxygen and chest compressions for $\geq 60$ seconds, epinephrine or volume expanders may be considered.

\section{Epinephrine}

If the heart rate is $<60$ beats/min despite optimizing ventilation and chest compressions, 0.01 to $0.03 \mathrm{mg} / \mathrm{kg}$ of epinephrine (diluted 1:10,000) must be administered intravenously (Class Ila, Level C-LD). If intravascular access is not yet available, higher 
doses of epinephrine $(0.05-0.1 \mathrm{mg} / \mathrm{kg})$ can be administered via an endotracheal tube (Class Ila, Level C-LD). However, administration of endotracheal epinephrine should not delay attempts to establish vascular access. If the response to endotracheal epinephrine is inadequate, intravenous administration should be performed as soon as vascular access is obtained, regardless of the interval after any initial endotracheal dose (Class Ila, Level C-LD). If the heart rate is consistently below 60 beats/min, additional intravenous administration of epinephrine is recommended every 3 to $5 \mathrm{~min}-$ utes (Class Ila, Level C-LD).

\section{Volume expander therapy}

Volume expander therapy was reviewed in the 2010 guideline ${ }^{17,18,186}$; there are no subsequent human studies. Early volume expansion with isotonic crystalloid or red blood cells is indicated for newborns with blood loss or suspected blood loss (pale skin, poor perfusion, and weak pulse) who do not respond to resuscitation (Class Ilb, Level C-EO). The recommended dose is $10 \mathrm{~mL} / \mathrm{kg}$, and repeated administration is possible if necessary. For preterm newborns, the administration should be as slow as possible to reduce the risk of complications such as intraventricular hemorrhage. ${ }^{187}$ There is little evidence on the administration of a volume expander when there is no response to resuscitation in newborns without blood loss.

\section{Intraosseous versus intravenous access}

Although few studies have shown successful administration of drugs and volume expanders through intraosseous injection in neonatal resuscitation, ${ }_{1}^{188,189}$ there are also reports of complications related to the use of intraosseous catheters. ${ }^{188,190-194}$ Therefore, it is reasonable to use the umbilical venous route as the primary method of vascular access during neonatal resuscitation in the delivery room (Class Ila, Level C-LD). If umbilical venous access is not feasible, the intraosseous route can be accessed as an alternative (Class Ila, Level C-LD).

Outside the delivery room setting, we suggest that the umbilical venous or intraosseous route be used depending on the equipment, training, and experience (Class Ilb, Level C-LD).

\section{POST-RESUSCITATION CARE}

\section{Post-resuscitation glucose management}

In newborns, both hypoglycemia and hyperglycemia increase the risk of brain injury and poor neurological prognosis. ${ }^{195-201}$ Therefore, blood glucose levels should be monitored immediately after resuscitation, and both hypoglycemia and hyperglycemia must be controlled through appropriate treatment (Class I, Level C-LD). The use of protocols to control blood glucose levels may avoid both hypoglycemia and hyperglycemia as well as prevent large swings in blood glucose levels.

\section{Therapeutic hypothermia Settings with sufficient resources}

In a meta-analysis of 8 RCTs involving 1,344 term and late preterm newborns with moderate-to-severe encephalopathy, therapeutic hypothermia significantly reduced the combined outcome of mortality or major neurodevelopmental disability to 18 months of age (odds ratio, $0.75 ; 95 \%$ confidence interval, 0.68-0.83). ${ }^{202}$ In newborns born at $\geq 36$ weeks of gestation with evolving moderate-to-severe hypoxic ischemic encephalopathy, therapeutic hypothermia, which must be executed in accordance with clearly defined protocols, i.e., cooling to commence within 6 hours, strict temperature control at $33^{\circ} \mathrm{C}$ to $34^{\circ} \mathrm{C}$ for 72 hours and rewarming over at least 4 hours, should be performed in neonatal care facilities with multidisciplinary approaches to treatment and long-term follow-up (Class I, Level A). ${ }^{203,204}$

\section{Settings with limited resources}

In settings with limited personnel and equipments, therapeutic hypothermia may be considered for term and late preterm newborns with evolving moderate-to-severe encephalopathy (Class IIb, Level B-R) ${ }^{205,206}$ Cooling should only be conducted under clearly defined protocols with treatment in neonatal care facilities with the multidisciplinary care.

\section{WITHHOLDING AND DISCONTINUING RESUSCITATION}

Non-initiation of resuscitation and withdrawal of cardiorespiratory support during or after resuscitation are ethically equivalent (Class I, Level C-EO). ${ }^{207,208}$ Treatment decisions for newborns who are on the lower limit of viability or who are expected to have high mortality and morbidities may depend on the treatment environment and available resources. Parents of severely ill newborns often want to play a large role in determining the initiation and maintenance of resuscitation. In the 2010 guideline, it was stated that the parents' views on resuscitation should be supported in conditions associated with uncertain prognosis, when there is borderline survival and a relatively high rate of morbidity and when the burden to the child is high. ${ }^{17,18}$ There have been no follow-up studies that could change the 2010 guidelines.

Prenatal judgments about the survival prognosis or disability of extremely preterm newborns are based on the GA. Several scoring systems involving variables such as sex, prenatal steroid use, 
and multiple gestations were developed to predict prognosis and can also be used to predict mortality and morbidity. ${ }^{41}$

\section{Withholding resuscitation}

When determining the prognosis of newborns with a $G A<25$ weeks immediately after birth, there was no other prediction method better than $\mathrm{GA}_{\text {; }}$ additionally, no other prediction method to help estimate the likelihood of survival during the first 18 to 22 months after birth. If the newborn is extremely preterm based on the GA and birth weight or the likelihood of survival is low due to congenital anomalies (e.g., predicted survival $<50 \%$, GA $<23$ weeks, birth weight $<400 \mathrm{~g}$, trisomy 13 or 18 , anencephaly), then resuscitation can be withheld. However, when advising families on the prognosis of newborns with a GA $<25$ weeks, the estimation of $G A$, presence of chorioamnionitis, and the level of medical service need to be considered on a case-by-case basis. Regional guidelines may affect whether resuscitation is appropriate for those with a GA $<25$ weeks (Class Ilb, Level C-LD). It is reasonable to obtain an expert opinion and discuss with the parents to determine withholding resuscitation for newborns who are at the lower limit of viability (Class Ila, Level C-EO). ${ }^{207,208}$

\section{Discontinuation of resuscitation}

In previous studies about the prognosis of newborns who underwent CPR for $\geq 10$ minutes after delivery, the proportion of those admitted to the neonatal intensive care unit and the proportion of surviving newborns were significantly different depending on the studies. ${ }^{209-222}$ Newborns who underwent CPR for $\geq 10-20$ minutes immediately after birth and did not show recovery of spontaneous circulation had a high risk of mortality and moderate-to-severe neurological impairment even if they survived. However, there is currently no evidence that a specific CPR duration is associated with death or neurological sequelae. The decision to discontinue resuscitation should be made on a case-by-case basis, and factors such as cause, GA, neonatal intensive care, and the application of neuroprotective strategies such as therapeutic hypothermia after resuscitation must also be considered. If all steps of CPR have been performed and continuous CPR is required, as spontaneous circulation is not restored after excluding reversible causes, discontinuation of CPR may be discussed with the team and family. Communication with the newborn's family is essential when deciding whether to discontinue resuscitation. The discussion can be considered at 10 to 20 minutes after birth (Class Ilb, Level C-LD). ${ }^{9-11}$

\section{RESUSCITATION TRAINING PROGRAM}

\section{Training for the medical staff}

Simulation must be a standard component in the training of neonatal resuscitation. ${ }^{187}$ The training frequency provided to the medical staff or medical school students did not affect the patients' prognostic outcomes (Level C-EO). However, training at intervals of $\leq 6$ months is particularly effective in improving psychomotor performance (Level B-R), knowledge, and confidence (Level C-LD) (Class Ilb, Level B-R). ${ }^{223,224}$ Therefore, neonatal resuscitation training, which is currently provided every 2 years, may need to be provided more often (Class Illb, Level C-LD). ${ }^{223,225-228}$

\section{Training for instructors}

There was no association between the provision of training to instructors involved in resuscitation and their performance. ${ }^{229,230}$ Until further studies on the optimal training method for instructors are reported, objectified, structured, and individualized training based on oral/written feedback may be considered (Class IIb, Level C-EO).

\section{EFFECTS OF BRIEFING AND DEBRIEFING}

A scoping review involving one $\mathrm{RCT}^{231}$ and three observational studies ${ }^{232-234}$ that assessed the effects of briefing and debriefing showed improvement in the knowledge and performance skills of the medical staff members as well as the short-term clinical outcomes of newborns. Therefore, briefing and debriefing for neonatal resuscitation are suggested (Class IIb, Level C-LD). The longterm effects have not yet been established, and there is a lack of evidence from systematic reviews. Therefore, further studies on the effects of briefing and debriefing are needed.

\section{CONFLICT OF INTEREST}

No potential conflict of interest relevant to this article was reported.

\section{ACKNOWLEDGMENTS}

This study was supported by a grant (2020E330300) of the Korean Disease Control and Prevention Agency funded by the Ministry of Health and Welfare, Republic of Korea.

We thank Ms. So Yeong Kim (EMT) for her assistance with administrative affairs and Mr. Myung Ha Kim for his assistance with literature searches for updating Korean Guidelines for cardiopulmonary resuscitation. We also thank the Korean Association of 
Cardiopulmonary Resuscitation (KACPR) for supporting the process of proofreading.

\section{REFERENCES}

1. Perlman JM, Wyllie J, Kattwinkel J, et al. Part 7: Neonatal resuscitation. 2015 International Consensus on Cardiopulmonary Resuscitation and Emergency Cardiovascular Care Science With Treatment Recommendations. Circulation 2015;132(16 Suppl 1):S204-41.

2. Polglase GR, Blank DA, Barton SK, et al. Physiologically based cord clamping stabilises cardiac output and reduces cerebrovascular injury in asphyxiated near-term lambs. Arch Dis Child Fetal Neonatal Ed 2018;103:F530-8.

3. Ersdal HL, Mduma E, Svensen E, Perlman JM. Early initiation of basic resuscitation interventions including face mask ventilation may reduce birth asphyxia related mortality in lowincome countries: a prospective descriptive observational study. Resuscitation 2012;83:869-73.

4. Ersdal HL, Linde J, Mduma E, Auestad B, Perlman J. Neonatal outcome following cord clamping after onset of spontaneous respiration. Pediatrics 2014;134:265-72.

5. Niles $D E$, Cines $C$, Insley $E$, et al. Incidence and characteristics of positive pressure ventilation delivered to newborns in a US tertiary academic hospital. Resuscitation 2017;115: 102-9.

6. Perlman JM, Risser R. Cardiopulmonary resuscitation in the delivery room. Associated clinical events. Arch Pediatr Adolesc Med 1995;149:20-5.

7. Halling C, Sparks JE, Christie L, Wyckoff MH. Efficacy of intravenous and endotracheal epinephrine during neonatal cardiopulmonary resuscitation in the delivery room. J Pediatr 2017;185:232-6.

8. Australian Institute of Health and Welfare. Australia's mothers and babies 2017: in brief [Internet]. Canberra: Australian Institute of Health and Welfare; 2017 [cited 2020 Feb 17]. Available from: https://www.aihw.gov.au/getmedia/2a0c22a2ba27-4ba0-ad47-ebbe51854cd6/aihw-per-100-in-brief. pdf.aspx?inline $=$ true.

9. Wyckoff MH, Weiner CGM; Neonatal Life Support Collaborators. 2020 International Consensus on Cardiopulmonary Resuscitation and Emergency Cardiovascular Care Science With Treatment Recommendations. Pediatrics 2021;147 (Suppl 1):e2020038505C.

10. Wyckoff MH, Wyllie J, Aziz K, et al. Neonatal Life Support: 2020 International Consensus on Cardiopulmonary Resuscitation and Emergency Cardiovascular Care Science With
Treatment Recommendations. Circulation 2020;142(16_ suppl_1):S185-221.

11. Wyckoff MH, Wyllie J, Aziz K, et al. Neonatal Life Support 2020 International Consensus on Cardiopulmonary Resuscitation and Emergency Cardiovascular Care Science With Treatment Recommendations. Resuscitation 2020;156:A15687.

12. Morrison $\mathrm{L}$, Gent $L M$, Lang $E$, et al. Part 2: evidence evaluation and management of conflicts of interest. 2015 American Heart Association guidelines update for cardiopulmonary resuscitation and emergency cardiovascular care. Circulation 2015;132(18 Suppl 2):S368-82.

13. Schunemann H, Brozek J, Guyatt G, Oxman A. GRADE handbook [Internet]. London: The Cochrane Collaboration; 2013 [cited 2020 Jul 4]. Available from: https://gdt.gradepro.org/ app/handbook/handbook.html.

14. Wyllie J, Bruinenberg J, Roehr CC, Rudiger M, Trevisanuto D, Urlesberger B. European Resuscitation Council Guidelines for Resuscitation 2015: section 7. Resuscitation and support of transition of babies at birth. Resuscitation 2015;95:24963.

15. Aziz K, Chadwick M, Baker M, Andrews W. Ante- and intrapartum factors that predict increased need for neonatal resuscitation. Resuscitation 2008;79:444-52.

16. Wyckoff MH, Aziz K, Escobedo MB, et al. Part 13: neonatal resuscitation. 2015 American Heart Association Guidelines Update for Cardiopulmonary Resuscitation and Emergency Cardiovascular Care (Reprint). Pediatrics 2015;136 Suppl 2:S196-218.

17. Perlman JM, Wyllie J, Kattwinkel J, et al. Part 11: neonatal resuscitation. 2010 International Consensus on Cardiopulmonary Resuscitation and Emergency Cardiovascular Care Science With Treatment Recommendations. Circulation 2010; 122(16 Suppl 2):S516-38.

18. Wyllie J, Perlman JM, Kattwinkel J, et al. Part 11: neonatal resuscitation. 2010 International Consensus on Cardiopulmonary Resuscitation and Emergency Cardiovascular Care Science with Treatment Recommendations. Resuscitation 2010;81 Suppl 1:e260-87.

19. Al-Tawil MM, Abdel-Aal MR, Kaddah MA. A randomized controlled trial on delayed cord clamping and iron status at 3-5 months in term neonates held at the level of maternal pelvis. J Neonatal Perinatal Med 2012;5:319-26.

20. Ceriani Cernadas JM, Carroli $G$, Pellegrini $L$, et al. The effect of timing of cord clamping on neonatal venous hematocrit values and clinical outcome at term: a randomized, controlled trial. Pediatrics 2006;117:e779-86. 
21. Chaparro CM, Neufeld LM, Tena Alavez G, Eguia-Liz Cedillo R, Dewey KG. Effect of timing of umbilical cord clamping on iron status in Mexican infants: a randomised controlled trial. Lancet 2006;367:1997-2004.

22. Chen $X$, Li X, Chang Y, Li W, Cui H. Effect and safety of timing of cord clamping on neonatal hematocrit values and clinical outcomes in term infants: a randomized controlled trial. J Perinatol 2018;38:251-7.

23. Chopra A, Thakur A, Garg P, Kler N, Gujral K. Early versus delayed cord clamping in small for gestational age infants and iron stores at 3 months of age: a randomized controlled trial. BMC Pediatr 2018;18:234.

24. Emhamed MO, van Rheenen P, Brabin BJ. The early effects of delayed cord clamping in term infants born to Libyan mothers. Trop Doct 2004;34:218-22.

25. Jahazi A, Kordi M, Mirbehbahani NB, Mazloom SR. The effect of early and late umbilical cord clamping on neonatal hematocrit. J Perinatol 2008;28:523-5.

26. Philip AG. Further observations on placental transfusion. Obstet Gynecol 1973;42:334-43.

27. Salari Z, Rezapour M, Khalili N. Late umbilical cord clamping, neonatal hematocrit and Apgar scores: a randomized controlled trial. J Neonatal Perinatal Med 2014;7:287-91.

28. Ultee $C A$, van der Deure J, Swart J, Lasham C, van Baar AL. Delayed cord clamping in preterm infants delivered at 3436 weeks' gestation: a randomised controlled trial. Arch Dis Child Fetal Neonatal Ed 2008;93:F20-3.

29. Vural I, Ozdemir H, Teker G, Yoldemir T, Bilgen H, Ozek E. Delayed cord clamping in term large-for-gestational age infants: a prospective randomised study. J Paediatr Child Health 2019;55:555-60.

30. Yadav AK, Upadhyay A, Gothwal S, Dubey K, Mandal U, Yadav CP. Comparison of three types of intervention to enhance placental redistribution in term newborns: randomized control trial. J Perinatol 2015;35:720-4.

31. Mercer JS, Erickson-Owens DA, Collins J, Barcelos MO, Parker $A B$, Padbury JF. Effects of delayed cord clamping on residual placental blood volume, hemoglobin and bilirubin levels in term infants: a randomized controlled trial. J Perinatol 2017;37:260-4.

32. Dong XY, Sun XF, Li MM, Yu ZB, Han SP. Influence of delayed cord clamping on preterm infants with a gestational age of <32 weeks. Zhongguo Dang Dai Er Ke Za Zhi 2016;18:635-8.

33. Fogarty $M$, Osborn DA, Askie $L$, et al. Delayed vs early umbilical cord clamping for preterm infants: a systematic review and meta-analysis. Am J Obstet Gynecol 2018;218:1-18.

34. Gokmen Z, Ozkiraz S, Tarcan A, Kozanoglu I, Ozcimen EE,
Ozbek N. Effects of delayed umbilical cord clamping on peripheral blood hematopoietic stem cells in premature neonates. J Perinat Med 2011;39:323-9.

35. McDonnell M, Henderson-Smart DJ. Delayed umbilical cord clamping in preterm infants: a feasibility study. J Paediatr Child Health 1997;33:308-10.

36. Oh W, Fanaroff $A A$, Carlo WA, et al. Effects of delayed cord clamping in very-low-birth-weight infants. J Perinatol 2011; 31 Suppl 1(Suppl 1):S68-71.

37. Rabe H, Diaz-Rossello JL, Duley L, Dowswell T. Effect of timing of umbilical cord clamping and other strategies to influence placental transfusion at preterm birth on maternal and infant outcomes. Cochrane Database Syst Rev 2012;(8):CD 003248.

38. Rabe H, Wacker A, Hulskamp G, et al. A randomised controlled trial of delayed cord clamping in very low birth weight preterm infants. Eur J Pediatr 2000;159:775-7.

39. Ruangkit $C$, Bumrungphuet $S$, Panburana $P$, Khositseth $A$, Nuntnarumit P. A randomized controlled trial of immediate versus delayed umbilical cord clamping in multiple-birth infants born preterm. Neonatology 2019;115:156-63.

40. Katheria A, Reister F, Essers J, et al. Association of umbilical cord milking vs delayed umbilical cord clamping with death or severe intraventricular hemorrhage among preterm infants. JAMA 2019;322:1877-86.

41. Wyckoff MH, Aziz K, Escobedo MB, et al. Part 13: neonatal resuscitation: 2015 American Heart Association Guidelines Update for Cardiopulmonary Resuscitation and Emergency Cardiovascular Care. Circulation 2015;132(18 Suppl 2):S54360.

42. Laptook AR, Salhab W, Bhaskar B; Neonatal Research Network. Admission temperature of low birth weight infants: predictors and associated morbidities. Pediatrics 2007;119: e643-9.

43. Lunze $\mathrm{K}$, Bloom DE, Jamison DT, Hamer DH. The global burden of neonatal hypothermia: systematic review of a major challenge for newborn survival. BMC Med 2013;11:24.

44. Lyu Y, Shah PS, Ye XY, et al. Association between admission temperature and mortality and major morbidity in preterm infants born at fewer than 33 weeks' gestation. JAMA Pediatr 2015;169:e150277.

45. World Health Organization. Thermal protection of the newborn: a practical guide. Geneva: World Health Organization; 1997.

46. Budin P. The nursling: the feeding and hygiene of premature and full-term infants. London: Caxton Publishing Company; 1907. 
47. McCarthy LK, Molloy EJ, Twomey AR, Murphy JF, O'Donnell $\mathrm{CP}$. A randomized trial of exothermic mattresses for preterm newborns in polyethylene bags. Pediatrics 2013;132:e13541.

48. Billimoria Z, Chawla S, Bajaj M, Natarajan G. Improving admission temperature in extremely low birth weight infants: a hospital-based multi-intervention quality improvement project. J Perinat Med 2013;41:455-60.

49. Chawla S, Amaram A, Gopal SP, Natarajan G. Safety and efficacy of Trans-warmer mattress for preterm neonates: results of a randomized controlled trial. J Perinatol 2011;31: 780-4.

50. Ibrahim CP, Yoxall CW. Use of self-heating gel mattresses eliminates admission hypothermia in infants born below 28 weeks gestation. Eur J Pediatr 2010;169:795-9.

51. Singh A, Duckett J, Newton T, Watkinson M. Improving neonatal unit admission temperatures in preterm babies: exothermic mattresses, polythene bags or a traditional approach? J Perinatol 2010;30:45-9.

52. Meyer MP, Payton MJ, Salmon A, Hutchinson $C$, de Klerk A. A clinical comparison of radiant warmer and incubator care for preterm infants from birth to 1800 grams. Pediatrics 2001;108:395-401.

53. te Pas AB, Lopriore E, Dito I, Morley CJ, Walther FJ. Humidified and heated air during stabilization at birth improves temperature in preterm infants. Pediatrics 2010;125:e142732.

54. DeMauro SB, Douglas E, Karp K, et al. Improving delivery room management for very preterm infants. Pediatrics 2013; 132:e1018-25.

55. Lee HC, Powers RJ, Bennett MV, et al. Implementation methods for delivery room management: a quality improvement comparison study. Pediatrics. 2014;134:e1378-86.

56. Russo A, McCready M, Torres $L$, et al. Reducing hypothermia in preterm infants following delivery. Pediatrics 2014;133: e1055-62.

57. Pinheiro JM, Furdon SA, Boynton $S$, Dugan R, Reu-Donlon $C$, Jensen $\mathrm{S}$. Decreasing hypothermia during delivery room stabilization of preterm neonates. Pediatrics 2014;133:e21826.

58. Donnellan D, Moore Z, Patton D, O'Connor T, Nugent L. The effect of thermoregulation quality improvement initiatives on the admission temperature of premature/very low birthweight infants in neonatal intensive care units: a systematic review. J Spec Pediatr Nurs 2020;25:e12286.

59. Amadi HO, Olateju EK, Alabi P, Kawuwa MB, Ibadin MO, Osibogun $\mathrm{A} 0$. Neonatal hyperthermia and thermal stress in low- and middle-income countries: a hidden cause of death in extremely low-birthweight neonates. Paediatr Int Child Health 2015;35:273-81.

60. Moore ER, Bergman N, Anderson GC, Medley N. Early skinto-skin contact for mothers and their healthy newborn infants. Cochrane Database Syst Rev 2016;11:CD003519.

61. Belsches TC, Tilly AE, Miller TR, et al. Randomized trial of plastic bags to prevent term neonatal hypothermia in a resource-poor setting. Pediatrics 2013;132:e656-61.

62. Feldman A, De Benedictis B, Alpan G, La Gamma EF, Kase J. Morbidity and mortality associated with rewarming hypothermic very low birth weight infants. J Neonatal Perinatal Med 2016;9:295-302.

63. Rech Morassutti F, Cavallin F, Zaramella P, Bortolus R, Parotto $M$, Trevisanuto $D$. Association of rewarming rate on neonatal outcomes in extremely low birth weight infants with hypothermia. J Pediatr 2015;167:557-61.

64. Petrova A, Demissie K, Rhoads GG, Smulian JC, Marcella S, Ananth CV. Association of maternal fever during labor with neonatal and infant morbidity and mortality. Obstet Gynecol 2001;98:20-7.

65. Alexander JM, McIntire DM, Leveno KJ. Chorioamnionitis and the prognosis for term infants. Obstet Gynecol 1999;94: 274-8.

66. Greenwell EA, Wyshak G, Ringer SA, Johnson LC, Rivkin MJ, Lieberman E. Intrapartum temperature elevation, epidural use, and adverse outcome in term infants. Pediatrics 2012; 129:e447-54.

67. Goetzl L, Manevich Y, Roedner C, Praktish A, Hebbar L, Townsend DM. Maternal and fetal oxidative stress and intrapartum term fever. Am J Obstet Gynecol 2010;202:363.

68. Glass HC, Pham TN, Danielsen B, Towner D, Glidden D, Wu YW. Antenatal and intrapartum risk factors for seizures in term newborns: a population-based study, California 19982002. J Pediatr 2009;154:24-8.

69. Lieberman E, Lang J, Richardson DK, Frigoletto FD, Heffner $\sqcup$, Cohen A. Intrapartum maternal fever and neonatal outcome. Pediatrics 2000;105(1 Pt 1):8-13.

70. Lieberman E, Eichenwald E, Mathur G, Richardson D, Heff-

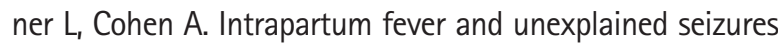
in term infants. Pediatrics 2000;106:983-8.

71. Badawi N, Kurinczuk JJ, Keogh JM, et al. Intrapartum risk factors for newborn encephalopathy: the Western Australian case-control study. BMJ 1998;317:1554-8.

72. Impey L, Greenwood C, MacQuillan K, Reynolds M, Sheil 0. Fever in labour and neonatal encephalopathy: a prospective cohort study. BJOG 2001;108:594-7. 
73. Impey LW, Greenwood CE, Black RS, Yeh PS, Sheil O, Doyle P. The relationship between intrapartum maternal fever and neonatal acidosis as risk factors for neonatal encephalopathy. Am J Obstet Gynecol 2008;198:49.

74. Linder N, Fridman $E_{1}$ Makhoul A, et al. Management of term newborns following maternal intrapartum fever. J Matern Fetal Neonatal Med 2013;26:207-10.

75. Butwick AJ, Lipman SS, Carvalho B. Intraoperative forced air-warming during cesarean delivery under spinal anesthesia does not prevent maternal hypothermia. Anesth Analg 2007;105:1413-9.

76. Fallis WM, Hamelin K, Symonds J, Wang X. Maternal and newborn outcomes related to maternal warming during cesarean delivery. J Obstet Gynecol Neonatal Nurs 2006;35: 324-31.

77. Horn EP, Schroeder F, Gottschalk $A$, et al. Active warming during cesarean delivery. Anesth Analg 2002;94:409-14.

78. Woolnough M, Allam J, Hemingway C, Cox M, Yentis SM. Intra-operative fluid warming in elective caesarean section: a blinded randomised controlled trial. Int J Obstet Anesth 2009;18:346-51.

79. Yokoyama $K$, Suzuki M, Shimada $Y$, Matsushima T, Bito $H_{\text {, }}$ Sakamoto A. Effect of administration of pre-warmed intravenous fluids on the frequency of hypothermia following spinal anesthesia for Cesarean delivery. J Clin Anesth 2009; 21:242-8.

80. Mullany LC, Katz J, Khatry SK, LeClerq SC, Darmstadt GL, Tielsch JM. Risk of mortality associated with neonatal hypothermia in southern Nepal. Arch Pediatr Adolesc Med 2010; 164:650-6.

81. Raman $\mathrm{S}$, Shahla A. Temperature drop in normal term newborn infants born at the University Hospital, Kuala Lumpur. Aust N Z J Obstet Gynaecol 1992;32:117-9.

82. Bergman NJ, Linley LL, Fawcus SR. Randomized controlled trial of skin-to-skin contact from birth versus conventional incubator for physiological stabilization in 1200- to 2199gram newborns. Acta Paediatr 2004;93:779-85.

83. Fardig JA. A comparison of skin-to-skin contact and radiant heaters in promoting neonatal thermoregulation. J Nurse Midwifery 1980;25:19-28.

84. Christensson K. Fathers can effectively achieve heat conservation in healthy newborn infants. Acta Paediatr 1996;85: 1354-60.

85. Christensson K, Siles C, Moreno L, et al. Temperature, metabolic adaptation and crying in healthy full-term newborns cared for skin-to-skin or in a cot. Acta Paediatr 1992;81: 488-93.
86. Bystrova K, Widstrom AM, Matthiesen AS, et al. Skin-toskin contact may reduce negative consequences of "the stress of being born": a study on temperature in newborn infants, subjected to different ward routines in St. Petersburg. Acta Paediatr 2003;92:320-6.

87. Gouchon S, Gregori D, Picotto A, Patrucco G, Nangeroni M, Di Giulio P. Skin-to-skin contact after cesarean delivery: an experimental study. Nurs Res 2010;59:78-84.

88. Marin Gabriel MA, Llana Martin I, Lopez Escobar A, Fernandez Villalba E, Romero Blanco I, Touza Pol P. Randomized controlled trial of early skin-to-skin contact: effects on the mother and the newborn. Acta Paediatr 2010;99:1630-4.

89. Nimbalkar SM, Patel VK, Patel DV, Nimbalkar AS, Sethi A, Phatak A. Effect of early skin-to-skin contact following normal delivery on incidence of hypothermia in neonates more than $1800 \mathrm{~g}$ : randomized control trial. J Perinatol 2014;34: 364-8.

90. Gungor S, Kurt E, Teksoz E, Goktolga U, Ceyhan T, Baser I. Oronasopharyngeal suction versus no suction in normal and term infants delivered by elective cesarean section: a prospective randomized controlled trial. Gynecol Obstet Invest 2006;61:9-14.

91. Gungor S, Teksoz E, Ceyhan T, Kurt E, Goktolga U, Baser I. Oronasopharyngeal suction versus no suction in normal, term and vaginally born infants: a prospective randomised controlled trial. Aust N Z J Obstet Gynaecol 2005;45:453-6.

92. McCartney PR. Bulb syringes in newborn care. MCN Am J Matern Child Nurs 2000;25:217.

93. Carrasco M, Martell M, Estol PC. Oronasopharyngeal suction at birth: effects on arterial oxygen saturation. J Pediatr 1997; 130:832-4.

94. Kohlhauser C, Bernert G, Hermon M, Popow C, Seidl R, Pollak $A$. Effects of endotracheal suctioning in high-frequency oscillatory and conventionally ventilated low birth weight neonates on cerebral hemodynamics observed by near infrared spectroscopy (NIRS). Pediatr Pulmonol 2000;29:270-5.

95. Skov L, Ryding J, Pryds 0, Greisen G. Changes in cerebral oxygenation and cerebral blood volume during endotracheal suctioning in ventilated neonates. Acta Paediatr 1992;81: 389-93.

96. van Bel $F$, van de Bor M, Baan J, Ruys JH. The influence of abnormal blood gases on cerebral blood flow velocity in the preterm newborn. Neuropediatrics 1988;19:27-32.

97. Perlman JM, Volpe JJ. Suctioning in the preterm infant: effects on cerebral blood flow velocity, intracranial pressure, and arterial blood pressure. Pediatrics 1983;72:329-34.

98. Fisher DM, Frewen T, Swedlow DB. Increase in intracranial 
pressure during suctioning: stimulation vs. rise in $\mathrm{PaCO} 2$. Anesthesiology 1982;57:416-7.

99. Simbruner G, Coradello H, Fodor M, Havelec L, Lubec G, Pollak $A$. Effect of tracheal suction on oxygenation, circulation, and lung mechanics in newborn infants. Arch Dis Child 1981; 56:326-30.

100. Konstantelos D, Ifflaender S, Dinger J, Rudiger M. Suctioning habits in the delivery room and the influence on postnatal adaptation: a video analysis. J Perinat Med 2015;43:777-82.

101. Foster JP, Dawson JA, Davis PG, Dahlen HG. Routine oro/nasopharyngeal suction versus no suction at birth. Cochrane Database Syst Rev 2017;4:CD010332.

102. Vain NE, Szyld EG, Prudent LM, Wiswell TE, Aguilar AM, Vivas NI. Oropharyngeal and nasopharyngeal suctioning of meconium-stained neonates before delivery of their shoulders: multicentre, randomised controlled trial. Lancet 2004; 364:597-602.

103. Chettri S, Adhisivam B, Bhat BV. Endotracheal suction for nonvigorous neonates born through meconium stained amniotic fluid: a randomized controlled trial. J Pediatr 2015; 166:1208-13.

104. Kumar A, Kumar P, Basu S. Endotracheal suctioning for prevention of meconium aspiration syndrome: a randomized controlled trial. Eur J Pediatr 2019;178:1825-32.

105. Nangia $S$, Sunder $S$, Biswas R, Saili A. Endotracheal suction in term non vigorous meconium stained neonates: a pilot study. Resuscitation 2016;105:79-84.

106. Singh SN, Saxena S, Bhriguvanshi A, Kumar M. Effect of endotracheal suctioning just after birth in non-vigorous infants born through meconium stained amniotic fluid: a randomized controlled trial. Clin Epidemiol Glob Health 2019;7: 165-70.

107. Chiruvolu A, Miklis KK, Chen E, Petrey B, Desai S. Delivery room management of meconium-stained newborns and respiratory support. Pediatrics 2018;142:e20181485.

108. Kalra VK, Lee HC, Sie L, Ratnasiri AW, Underwood MA, Lakshminrusimha $\mathrm{S}$. Change in neonatal resuscitation guidelines and trends in incidence of meconium aspiration syndrome in California. J Perinatol 2020;40:46-55.

109. Myers P, Gupta AG. Impact of the revised NRP Meconium Aspiration Guidelines on Term Infant Outcomes. Hosp Pediatr 2020;10:295-9.

110. Lee $A C$, Cousens $S$, Wall $S N$, et al. Neonatal resuscitation and immediate newborn assessment and stimulation for the prevention of neonatal deaths: a systematic review, metaanalysis and Delphi estimation of mortality effect. BMC Public Health 2011;11 Suppl 3(Suppl 3):S12.
111. American Academy of Pediatrics; American Heart Association. Textbook of neonatal resuscitation. 7th ed. Elk Grove Village, IL: American Academy of Pediatrics; 2016.

112. Kalaniti K, Chacko A, Daspal S. Tactile stimulation during newborn resuscitation: the good, the bad, and the ugly. Oman Med J 2018;33:84-5.

113. Japan Society of Perinatal and Neonatal Medicine. The textbook of neonatal cardiopulmonary resuscitation based on the 2015 Guidelines of the Japan Resuscitation Council 3rd ed. Tokyo: Medical View; 2016.

114. Voogdt KG, Morrison AC, Wood FE, van Elburg RM, Wyllie JP. A randomised, simulated study assessing auscultation of heart rate at birth. Resuscitation 2010;81:1000-3.

115. Dawson JA, Saraswat $A$, Simionato $L$, et al. Comparison of heart rate and oxygen saturation measurements from Masimo and Nellcor pulse oximeters in newly born term infants. Acta Paediatr 2013;102:955-60.

116. Kamlin CO, Dawson JA, O'Donnell $C P$, et al. Accuracy of pulse oximetry measurement of heart rate of newborn infants in the delivery room. J Pediatr 2008;152:756-60.

117. van Vonderen JJ, Hooper SB, Kroese JK, et al. Pulse oximetry measures a lower heart rate at birth compared with electrocardiography. J Pediatr 2015;166:49-53.

118. Anton 0 , Fernandez R, Rendon-Morales E, Aviles-Espinosa R, Jordan $\mathrm{H}$, Rabe $\mathrm{H}$. Heart rate monitoring in newborn babies: a systematic review. Neonatology 2019;116:199-210.

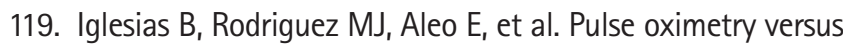
electrocardiogram for heart rate assessment during resuscitation of the preterm infant. An Pediatr (Barc) 2016;84:271-7.

120. Gulati R, Zayek M, Eyal F. Presetting ECG electrodes for earlier heart rate detection in the delivery room. Resuscitation 2018;128:83-7.

121. Iglesias B, Rodri Guez MAJ, Aleo E, Criado E, Marti Nez-Orgado J, Arruza L. 3-lead electrocardiogram is more reliable than pulse oximetry to detect bradycardia during stabilisation at birth of very preterm infants. Arch Dis Child Fetal Neonatal Ed 2018;103:F233-7.

122. Schmolzer GM, Morley CJ, Wong C, et al. Respiratory function monitor guidance of mask ventilation in the delivery room: a feasibility study. J Pediatr 2012;160:377-81.

123. Kong JY, Rich W, Finer NN, Leone TA. Quantitative end-tidal carbon dioxide monitoring in the delivery room: a randomized controlled trial. J Pediatr 2013;163:104-8.

124. Wyllie J, Perlman JM, Kattwinkel J, et al. Part 7: Neonatal resuscitation. 2015 International Consensus on Cardiopulmonary Resuscitation and Emergency Cardiovascular Care Science with Treatment Recommendations. Resuscitation 
2015;95:e169-201.

125. Lindner W, Hogel J, Pohlandt F. Sustained pressure-controlled inflation or intermittent mandatory ventilation in preterm infants in the delivery room? A randomized, controlled trial on initial respiratory support via nasopharyngeal tube. Acta Paediatr 2005;94:303-9.

126. Lista G, Boni L, Scopesi F, et al. Sustained lung inflation at birth for preterm infants: a randomized clinical trial. Pediatrics 2015;135:e457-64.

127. Schwaberger B, Pichler G, Avian A, Binder-Heschl C, Baik N, Urlesberger $B$. Do sustained lung inflations during neonatal resuscitation affect cerebral blood volume in preterm infants? A randomized controlled pilot study. PLoS One 2015; 10:e0138964.

128. Jiravisitkul P, Rattanasiri S, Nuntnarumit P. Randomised controlled trial of sustained lung inflation for resuscitation of preterm infants in the delivery room. Resuscitation 2017;111: 68-73.

129. Ngan AY, Cheung PY, Hudson-Mason A, et al. Using exhaled $\mathrm{CO} 2$ to guide initial respiratory support at birth: a randomised controlled trial. Arch Dis Child Fetal Neonatal Ed 2017;102: F525-31.

130. El-Chimi MS, Awad HA, El-Gammasy TM, El-Farghali OG, Sallam MT, Shinkar DM. Sustained versus intermittent lung inflation for resuscitation of preterm infants: a randomized controlled trial. J Matern Fetal Neonatal Med 2017;30:1273-8.

131. Abd El-Fattah N, Nasef N, Al-Harrass MF, Khashaba M. Sustained lung inflation at birth for preterm infants at risk of respiratory distress syndrome: the proper pressure and duration. J Neonatal Perinatal Med 2017;10:409-17.

132. La Verde A, Franchini $S$, Lapergola $G$, et al. Effects of sustained inflation or positive pressure ventilation on the release of adrenomedullin in preterm infants with respiratory failure at birth. Am J Perinatol 2019;36(S 02):S110-14.

133. Kirpalani $H$, Ratcliffe $S J$, Keszler $M$, et al. Effect of sustained inflations vs intermittent positive pressure ventilation on bronchopulmonary dysplasia or death among extremely preterm infants: the SAIL randomized clinical trial. JAMA 2019;321:1165-75.

134. Mercadante D, Colnaghi M, Polimeni V, et al. Sustained lung inflation in late preterm infants: a randomized controlled trial. J Perinatol 2016;36:443-7.

135. Perlman JM, Wyllie J, Kattwinkel J, et al. Part 7: neonatal resuscitation. 2015 International Consensus on Cardiopulmonary Resuscitation and Emergency Cardiovascular Care Science With Treatment Recommendations (Reprint). Pediatrics 2015;136 Suppl 2:S120-66.
136. Dawson JA, Schmolzer GM, Kamlin CO, et al. Oxygenation with T-piece versus self-inflating bag for ventilation of extremely preterm infants at birth: a randomized controlled trial. J Pediatr 2011;158:912-8.

137. Szyld E, Aguilar A, Musante GA, et al. Comparison of devices for newborn ventilation in the delivery room. J Pediatr 2014; 165:234-9.

138. Dawson JA, Gerber A, Kamlin CO, Davis PG, Morley CJ. Providing PEEP during neonatal resuscitation: which device is best? J Paediatr Child Health 2011;47:698-703.

139. Morley CJ, Dawson JA, Stewart MJ, Hussain F, Davis PG. The effect of a PEEP valve on a Laerdal neonatal self-inflating resuscitation bag. J Paediatr Child Health 2010;46:51-6.

140. Bennett $S$, Finer NN, Rich $W$, Vaucher $Y$. A comparison of three neonatal resuscitation devices. Resuscitation 2005;67: 113-8.

141. Kelm M, Proquitte $H$, Schmalisch $G$, Roehr CC. Reliability of two common PEEP-generating devices used in neonatal resuscitation. Klin Padiatr 2009;221:415-8.

142. Oddie S, Wyllie J, Scally A. Use of self-inflating bags for neonatal resuscitation. Resuscitation 2005;67:109-12.

143. Hussey SG, Ryan CA, Murphy BP. Comparison of three manual ventilation devices using an intubated mannequin. Arch Dis Child Fetal Neonatal Ed 2004;89:F490-3.

144. Finer NN, Rich W, Craft A, Henderson C. Comparison of methods of bag and mask ventilation for neonatal resuscitation. Resuscitation 2001;49:299-305.

145. Guinsburg R, de Almeida MFB, de Castro JS, et al. T-piece versus self-inflating bag ventilation in preterm neonates at birth. Arch Dis Child Fetal Neonatal Ed 2018;103:F49-55.

146. Thakur A, Saluja S, Modi M, et al. T-piece or self inflating bag for positive pressure ventilation during delivery room resuscitation: an RCT. Resuscitation 2015;90:21-4.

147. Qureshi MJ, Kumar M. Laryngeal mask airway versus bagmask ventilation or endotracheal intubation for neonatal resuscitation. Cochrane Database Syst Rev 2018;3:CD00 3314.

148. Morley CJ, Davis PG, Doyle LW, et al. Nasal CPAP or intubation at birth for very preterm infants. N Engl J Med 2008; 358:700-8.

149. SUPPORT Study Group of the Eunice Kennedy Shriver NICHD Neonatal Research Network, Finer NN, Carlo WA, et al. Early CPAP versus surfactant in extremely preterm infants. $N$ Engl J Med 2010;362:1970-9.

150. Dunn MS, Kaempf J, de Klerk A, et al. Randomized trial comparing 3 approaches to the initial respiratory management of preterm neonates. Pediatrics 2011;128:e1069-76. 


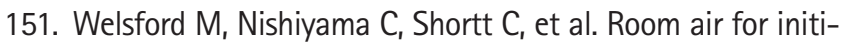
ating term newborn resuscitation: a systematic review with meta-analysis. Pediatrics 2019;143:e20181825.

152. Mariani G, Dik PB, Ezquer A, et al. Pre-ductal and post-ductal 02 saturation in healthy term neonates after birth. J Pediatr 2007;150:418-21.

153. Lundstrom KE, Pryds O, Greisen G. Oxygen at birth and prolonged cerebral vasoconstriction in preterm infants. Arch Dis Child Fetal Neonatal Ed 1995;73:F81-6.

154. Harling AE, Beresford MW, Vince GS, Bates M, Yoxall CW. Does sustained lung inflation at resuscitation reduce lung injury in the preterm infant? Arch Dis Child Fetal Neonatal Ed 2005;90:F406-10.

155. Wang CL, Anderson C, Leone TA, Rich W, Govindaswami B, Finer NN. Resuscitation of preterm neonates by using room air or 100\% oxygen. Pediatrics 2008;121:1083-9.

156. Vento $M$, Moro $M$, Escrig $R$, et al. Preterm resuscitation with low oxygen causes less oxidative stress, inflammation, and chronic lung disease. Pediatrics 2009;124:e439-49.

157. Rabi Y, Singhal N, Nettel-Aguirre A. Room-air versus oxygen administration for resuscitation of preterm infants: the ROAR study. Pediatrics 2011;128:e374-81.

158. Armanian AM, Badiee Z. Resuscitation of preterm newborns with low concentration oxygen versus high concentration oxygen. J Res Pharm Pract 2012;1:25-9.

159. Kapadia VS, Chalak LF, Sparks JE, Allen JR, Savani RC, Wyckoff MH. Resuscitation of preterm neonates with limited versus high oxygen strategy. Pediatrics 2013;132:e1488-96.

160. Aguar M, Brugada M, Escobar J, et al. Resuscitation of ELBW infants with initial $\mathrm{FiO} 2$ of $30 \%$ vs. $60 \%$, a randomized, controlled, blinded study: the REOX trial. In: 2013 Pediatric Academic Societies' Annual Meeting; 2013 May 4-7; Washington, DC, USA. Vancouver: Pediatric Academic Societies; 2013. p. 4-7.

161. Rook $D$, Schierbeek $H$, Vento $M$, et al. Resuscitation of preterm infants with different inspired oxygen fractions. J Pediatr 2014;164:1322-6.

162. Boronat N, Aguar M, Rook D, et al. Survival and neurodevelopmental outcomes of preterms resuscitated with different oxygen fractions. Pediatrics 2016;138:e20161405.

163. Thamrin V, Saugstad OD, Tarnow-Mordi W, et al. Preterm infant outcomes after randomization to initial resuscitation with FiO(2) 0.21 or 1.0. J Pediatr 2018;201:55-61.

164. Oei JL, Saugstad OD, Lui K, et al. Targeted oxygen in the resuscitation of preterm infants, a randomized clinical trial. Pediatrics 2017;139:e20161452.

165. Kapadia VS, Lal CV, Kakkilaya V, Heyne R, Savani RC, Wyck- off MH. Impact of the neonatal resuscitation program-recommended low oxygen strategy on outcomes of infants born preterm. J Pediatr 2017;191:35-41.

166. Soraisham AS, Rabi Y, Shah PS, et al. Neurodevelopmental outcomes of preterm infants resuscitated with different oxygen concentration at birth. J Perinatol 2017;37:1141-7.

167. Dawson JA, Kamlin CO, Wong C, et al. Oxygen saturation and heart rate during delivery room resuscitation of infants $<30$ weeks' gestation with air or 100\% oxygen. Arch Dis Child Fetal Neonatal Ed 2009;94:F87-91.

168. Rabi Y, Lodha A, Soraisham A, Singhal N, Barrington K, Shah PS. Outcomes of preterm infants following the introduction of room air resuscitation. Resuscitation 2015;96:252-9.

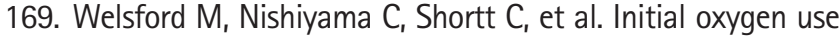
for preterm newborn resuscitation: a systematic review with meta-analysis. Pediatrics 2019;143:e20181828.

170. Dekker J, Martherus T, Lopriore $E_{1}$ et al. The effect of initial high vs. low FiO2 on breathing effort in preterm infants at birth: a randomized controlled trial. Front Pediatr 2019;7: 504.

171. Thio $M$, van Kempen $L$, Rafferty $A R$, Bhatia $R$, Dawson JA, Davis PG. Neonatal resuscitation in resource-limited settings: titrating oxygen delivery without an oxygen blender. $J$ Pediatr 2014;165:256-60.

172. Saini SS, Gupta N, Kumar P, Bhalla AK, Kaur H. A comparison of two-fingers technique and two-thumbs encircling hands technique of chest compression in neonates. J Perinatol 2012;32:690-4.

173. You Y. Optimum location for chest compressions during two-rescuer infant cardiopulmonary resuscitation. Resuscitation 2009;80:1378-81.

174. Meyer A, Nadkarni V, Pollock A, et al. Evaluation of the Neonatal Resuscitation Program's recommended chest compression depth using computerized tomography imaging. Resuscitation 2010;81:544-8.

175. Christman C, Hemway RJ, Wyckoff MH, Perlman JM. The two-thumb is superior to the two-finger method for administering chest compressions in a manikin model of neonatal resuscitation. Arch Dis Child Fetal Neonatal Ed 2011;96:F99101.

176. Martin PS, Kemp AM, Theobald PS, Maguire SA, Jones MD. Do chest compressions during simulated infant CPR comply with international recommendations? Arch Dis Child 2013; 98:576-81.

177. Park J, Yoon C, Lee JC, et al. Manikin-integrated digital measuring system for assessment of infant cardiopulmonary resuscitation techniques. IEEE J Biomed Health Inform 2014;18: 
1659-67.

178. David R. Closed chest cardiac massage in the newborn infant. Pediatrics 1988;81:552-4.

179. Pasquin MP, Cheung PY, Patel $S$, et al. Comparison of different compression to ventilation ratios $(2: 1,3: 1$, and $4: 1)$ during cardiopulmonary resuscitation in a porcine model of neonatal asphyxia. Neonatology 2018;114:37-45.

180. Schmolzer GM, O'Reilly M, Labossiere J, et al. 3:1 compression to ventilation ratio versus continuous chest compression with asynchronous ventilation in a porcine model of neonatal resuscitation. Resuscitation 2014;85:270-5.

181. Solevag AL, Dannevig I, Wyckoff M, Saugstad OD, Nakstad B. Extended series of cardiac compressions during CPR in a swine model of perinatal asphyxia. Resuscitation 2010;81: 1571-6.

182. Solevag AL, Dannevig I, Wyckoff M, Saugstad OD, Nakstad B. Return of spontaneous circulation with a compression:ventilation ratio of 15:2 versus $3: 1$ in newborn pigs with cardiac arrest due to asphyxia. Arch Dis Child Fetal Neonatal Ed 2011;96:F417-21.

183. Solevag AL, Schmolzer GM, O'Reilly M, et al. Myocardial perfusion and oxidative stress after $21 \%$ vs. 100\% oxygen ventilation and uninterrupted chest compressions in severely asphyxiated piglets. Resuscitation 2016;106:7-13.

184. Garcia-Hidalgo $C$, Cheung PY, Solevag AL, et al. A review of oxygen use during chest compressions in newborns: a metaanalysis of animal data. Front Pediatr 2018;6:400.

185. Chalak LF, Barber CA, Hynan L, Garcia D, Christie L, Wyckoff $\mathrm{MH}$. End-tidal $\mathrm{CO} 2$ detection of an audible heart rate during neonatal cardiopulmonary resuscitation after asystole in asphyxiated piglets. Pediatr Res 2011;69(5 Pt 1):401-5.

186. Perlman JM, Wyllie J, Kattwinkel J, et al. Neonatal resuscitation: 2010 International Consensus on Cardiopulmonary Resuscitation and Emergency Cardiovascular Care Science with Treatment Recommendations. Pediatrics 2010;126:e131944.

187. Kattwinkel J, Perlman JM, Aziz K, et al. Part 15: neonatal resuscitation. 2010 American Heart Association Guidelines for Cardiopulmonary Resuscitation and Emergency Cardiovascular Care. Circulation 2010;122(18 Suppl 3):S909-19.

188. Ellemunter $H$, Simma B, Trawoger $R$, Maurer $H$. Intraosseous lines in preterm and full term neonates. Arch Dis Child Fetal Neonatal Ed 1999;80:F74-5.

189. Wagner $M$, Olischar $M, 0$ 'Reilly $M$, et al. Review of routes to administer medication during prolonged neonatal resuscitation. Pediatr Crit Care Med 2018;19:332-8.

190. Vidal R, Kissoon N, Gayle M. Compartment syndrome fol- lowing intraosseous infusion. Pediatrics 1993;91:1201-2.

191. Carreras-Gonzalez E, Brio-Sanagustin S, Guimera I, Crespo C. Complication of the intraosseous route in a newborn infant. Med Intensiva 2012;36:233-4.

192. Katz DS, Wojtowycz AR. Tibial fracture: a complication of intraosseous infusion. Am J Emerg Med 1994;12:258-9.

193. Oesterlie GE, Petersen KK, Knudsen L, Henriksen TB. Crural amputation of a newborn as a consequence of intraosseous needle insertion and calcium infusion. Pediatr Emerg Care 2014;30:413-4.

194. Suominen PK, Nurmi E, Lauerma K. Intraosseous access in neonates and infants: risk of severe complications: a case report. Acta Anaesthesiol Scand 2015;59:1389-93.

195. Castrodale V, Rinehart S. The golden hour: improving the stabilization of the very low birth-weight infant. Adv Neonatal Care 2014;14:9-14.

196. McKinlay CJ, Alsweiler JM, Ansell JM, et al. Neonatal glycemia and neurodevelopmental outcomes at 2 years. $\mathrm{N}$ Engl J Med 2015;373:1507-18.

197. Nadeem M, Murray DM, Boylan GB, Dempsey EM, Ryan CA. Early blood glucose profile and neurodevelopmental outcome at two years in neonatal hypoxic-ischaemic encephalopathy. BMC Pediatr 2011;11:10.

198. Pinchefsky EF, Hahn CD, Kamino D, et al. Hyperglycemia and glucose variability are associated with worse brain function and seizures in neonatal encephalopathy: a prospective cohort study. J Pediatr 2019;209:23-32.

199. Salhab WA, Wyckoff MH, Laptook AR, Perlman JM. Initial hypoglycemia and neonatal brain injury in term infants with severe fetal acidemia. Pediatrics 2004;114:361-6.

200. Shah BR, Sharifi F. Perinatal outcomes for untreated women with gestational diabetes by IADPSG criteria: a populationbased study. BJOG 2020;127:116-22.

201. Tan JKG, Minutillo C, McMichael J, Rao S. Impact of hypoglycaemia on neurodevelopmental outcomes in hypoxic ischaemic encephalopathy: a retrospective cohort study. BMJ Paediatr Open 2017;1:e000175.

202. Jacobs SE, Berg M, Hunt R, Tarnow-Mordi WO, Inder TE, Davis PG. Cooling for newborns with hypoxic ischaemic encephalopathy. Cochrane Database Syst Rev 2013;2013:CD003311.

203. Aziz K, Lee HC, Escobedo MB, et al. Part 5: neonatal resuscitation. 2020 American Heart Association Guidelines for Cardiopulmonary Resuscitation and Emergency Cardiovascular Care. Circulation 2020;142(16_suppl_2):S524-50.

204. Aziz K, Lee CHC, Escobedo MB, et al. Part 5: Neonatal Resuscitation 2020 American Heart Association Guidelines for Cardiopulmonary Resuscitation and Emergency Cardiovas- 
cular Care. Pediatrics 2021;147(Suppl 1):e2020038505E.

205. Bharadwaj SK, Bhat BV. Therapeutic hypothermia using gel packs for term neonates with hypoxic ischaemic encephalopathy in resource-limited settings: a randomized controlled trial. J Trop Pediatr 2012;58:382-8.

206. Jacobs SE, Morley CJ, Inder TE, et al. Whole-body hypothermia for term and near-term newborns with hypoxic-ischemic encephalopathy: a randomized controlled trial. Arch Pediatr Adolesc Med 2011;165:692-700.

207. American Academy of Pediatrics Committee on Fetus and Newborn, Bell EF. Noninitiation or withdrawal of intensive care for high-risk newborns. Pediatrics 2007;119:401-3.

208. Cummings J; Committee on Fetus and Newborn. Antenatal counseling regarding resuscitation and intensive care before 25 weeks of gestation. Pediatrics 2015;136:588-95.

209. Harrington DJ, Redman CW, Moulden M, Greenwood CE. The long-term outcome in surviving infants with Apgar zero at 10 minutes: a systematic review of the literature and hospital-based cohort. Am J Obstet Gynecol 2007;196:463.

210. Casalaz DM, Marlow N, Speidel BD. Outcome of resuscitation following unexpected apparent stillbirth. Arch Dis Child Fetal Neonatal Ed 1998;78:F112-5.

211. Haddad B, Mercer BM, Livingston JC, Talati A, Sibai BM. Outcome after successful resuscitation of babies born with apgar scores of 0 at both 1 and 5 minutes. Am J Obstet Gynecol 2000;182:1210-4.

212. Jain L, Ferre C, Vidyasagar D, Nath S, Sheftel D. Cardiopulmonary resuscitation of apparently stillborn infants: survival and long-term outcome. J Pediatr 1991;118:778-82.

213. Kasdorf E, Laptook A, Azzopardi D, Jacobs S, Perlman JM. Improving infant outcome with a 10 min Apgar of 0. Arch Dis Child Fetal Neonatal Ed 2015;100:F102-5.

214. Natarajan $G$, Shankaran $S$, Laptook AR, et al. Apgar scores at $10 \mathrm{~min}$ and outcomes at 6-7 years following hypoxic-ischaemic encephalopathy. Arch Dis Child Fetal Neonatal Ed 2013;98:F473-9.

215. Sarkar S, Bhagat I, Dechert RE, Barks JD. Predicting death despite therapeutic hypothermia in infants with hypoxicischaemic encephalopathy. Arch Dis Child Fetal Neonatal Ed 2010;95:F423-8.

216. Shah $P$, Anvekar A, McMichael J, Rao S. Outcomes of infants with Apgar score of zero at $10 \mathrm{~min}$ : the West Australian experience. Arch Dis Child Fetal Neonatal Ed 2015;100:F492-4.

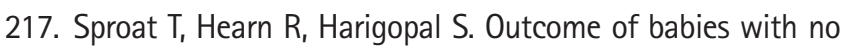
detectable heart rate before 10 minutes of age, and the effect of gestation. Arch Dis Child Fetal Neonatal Ed 2017;102: F262-5.
218. Shibasaki J, Mukai T, Tsuda K, et al. Outcomes related to 10min Apgar scores of zero in Japan. Arch Dis Child Fetal Neonatal Ed 2020;105:64-8.

219. Patel H, Beeby PJ. Resuscitation beyond 10 minutes of term babies born without signs of life. J Paediatr Child Health 2004;40:136-8.

220. Socol ML, Garcia PM, Riter S. Depressed Apgar scores, acidbase status, and neurologic outcome. Am J Obstet Gynecol 1994;170:991-8.

221. Ayrapetyan $M$, Carola $D$, Lakshminrusimha $S$, Bhandari $V$, Aghai ZH. Infants born to mothers with clinical chorioamnionitis: a cross-sectional survey on the use of early-onset sepsis risk calculator and prolonged use of antibiotics. Am J Perinatol 2019;36:428-33.

222. Zhang SQ, Friedman H, Strand ML. Length of resuscitation for severely depressed newborns. Am J Perinatol 2020;37: 933-8.

223. Ernst KD, Cline WL, Dannaway DC, et al. Weekly and consecutive day neonatal intubation training: comparable on a pediatrics clerkship. Acad Med 2014;89:505-10.

224. Mosley CM, Shaw BN. A longitudinal cohort study to investigate the retention of knowledge and skills following attendance on the Newborn Life support course. Arch Dis Child 2013;98:582-6.

225. Bender J, Kennally K, Shields R, Overly F. Does simulation booster impact retention of resuscitation procedural skills and teamwork? J Perinatol 2014;34:664-8.

226. Tabangin ME, Josyula S, Taylor KK, Vasquez JC, Kamath-Rayne BD. Resuscitation skills after Helping Babies Breathe training: a comparison of varying practice frequency and impact on retention of skills in different types of providers. Int Health 2018;10:163-71.

227. Mduma E, Ersdal $H_{\text {, Svensen }} E_{1}$ Kidanto $H_{1}$ Auestad B, Perlman J. Frequent brief on-site simulation training and reduction in 24-h neonatal mortality: an educational intervention study. Resuscitation 2015;93:1-7.

228. Reisman J, Arlington L, Jensen L, Louis $H$, Suarez-Rebling $D$, Nelson BD. Newborn resuscitation training in resource-limited settings: a systematic literature review. Pediatrics 2016; 138:e20154490.

229. Breckwoldt J, Svensson J, Lingemann C, Gruber H. Does clinical teacher training always improve teaching effectiveness as opposed to no teacher training? A randomized controlled study. BMC Med Educ 2014;14:6.

230. Boerboom TB, Jaarsma D, Dolmans DH, Scherpbier AJ, Mastenbroek NJ, Van Beukelen P. Peer group reflection helps clinical teachers to critically reflect on their teaching. Med 
Teach 2011;33:e615-23.

231. Magee MJ, Farkouh-Karoleski C, Rosen TS. Improvement of immediate performance in neonatal resuscitation through rapid cycle deliberate practice training. J Grad Med Educ 2018;10:192-7.

232. Skare $C$, Calisch $T E$, Saeter $E$, et al. Implementation and effectiveness of a video-based debriefing programme for neonatal resuscitation. Acta Anaesthesiol Scand 2018;62:394-
403.

233. Sauer CW, Boutin MA, Fatayerji AN, et al. Delivery room quality improvement project improved compliance with best practices for a community NICU. Sci Rep 2016;6:37397.

234. Katheria A, Rich W, Finer N. Development of a strategic process using checklists to facilitate team preparation and improve communication during neonatal resuscitation. Resuscitation 2013;84:1552-7. 